\section{A invenção do Brasil na encruzilhada de dois mundos}

\section{Adriana Romeiro [*]}

[*] Professora associada da Universidade Federal de Minas Gerais (UFMG). Belo Horizonte (MG), Brasil.. adriana.romeiro@uol.com.br

ORCID: http://orcid.org/0000-0002-9864-5346

\section{MALERBA, Jurandir.}

Brasil em projetos: história dos sucessos políticose planos de melhoramento do reino: da ilustração portuguesa à Independência do Brasil. Rio de Janeiro: FGV Editora, 2020. 416p.
Resumo: O novo livro de Jurandir Malerba examina os sucessivos projetos formulados para o Brasil, entre meados do século XVIII e as primeiras décadas do século XIX. A resenha busca situar a contribuição desse trabalho à historiografia sobre o período.

Palavras-chave: Brasil; Independência; Reformismo Ilustrado.

\section{The invention of Brazil at} the crossroads of two worlds

Abstract: Jurandir Malerba's new book examines the successive projects formulated for Brazil, between the middle of the 18 th century and the first decades of the 19th century. The review aims to situate the contribution of this work to historiog raphy about the period.

Keywords: Brazil; Independence; Illustrated Reformism 

rasil em projetos é, sobretudo, uma obra de síntese. Em suas páginas, Jurandir Malerba oferece uma interpretação sobre o processo de criação do Brasil, uma forma de pensá-lo, uma perspectiva teórica que lhe dá sentido e inteligibilidade. E, por essa razão, foge das análises estreitas e miúdas, presas aos eventos e muito rentes às fontes, que parecem sugerir que a tarefa do historiador devesse se esgotar nessa espécie de artesanato laborioso e pouco reflexivo. Aliás, o apego exagerado à empiria e a desconfiança da teoria que, nas últimas décadas, deram o tom na historiografia brasileira, parecem deslocados nos dias de hoje, quando os desafios exigem sínteses mais arrojadas, sobretudo a respeito de aspectos mais centrais e decisivos do passado, capazes de explicar um presente que nos desconcerta e angustia.

O livro trata dos projetos, planos, ideias e sistemas que foram formulados, entre meados do século XVIII - no âmbito do reformismo ilustrado - até os anos que se seguiram à Independência, tendo como eixo os escritos de reformadores como Rodrigo de Sousa Coutinho, José Joaquim da Cunha de Azeredo Coutinho, José da Silva Lisboa e José Bonifácio de Andrada e Silva. Em comum, todos eles partilhavam da convicção de que era preciso encontrar soluções para o Brasil, tarefa à qual se dedicaram com grande labor, num período particularmente turbulento, em que o país transitou do estatuto de colônia no Império português à nação independente, passando pela categoria de reino, com a criação do Reino Unido de Portugal, Brasil e Algarves, em 1815. É, portanto, nesse arco de tempo de mais de setenta anos que se situam as reformas empreendidas por Sebastião José de Carvalho e Melo, com vistas à modernização de Portugal e de suas colônias, e a atuação da célebre geração de 1790, nome que se deu ao grupo formado por letrados sob a influência do secretário de Estado da Marinha e Domínios Ultramarinos, Rodrigo de Sousa Coutinho, como José Joaquim da Cunha de Azeredo Coutinho e José Bonifácio de Andrada e Silva. De diferentes formas, em meio aos estertores do Antigo Regime e o advento de uma nova época, o olhar desses homens convergiu para o Brasil: se, para alguns, tratou-se de garantir a preservação dos vínculos com Portugal, de modo a aprofundar a exploração colonial, drenando, com mais eficiência, o fluxo de riquezas da periferia para o centro; para outros, como José Bonifácio, o desafio consistiu em formular um futuro para a nova nação independente.

A proposta de uma síntese dos projetos formulados para o Brasil no interior de um recorte cronológico mais amplo é uma das contribuições originais desse estudo. Evidentemente, tópicos como o reformismo ilustrado, as propostas formuladas pela geração de 1790 e os debates em torno da construção da nação independente não só constituem pontos programáticos desse campo de investigação, mas também resultaram em algumas obras canônicas, como as de Charles R. Boxer (2001), Fernando Novais (1986), Kenneth Maxwell (1973), Valentim Alexandre (1993), Francisco José Calazans Falcon (1982), István Jancsó (2005). 
No entanto, uma obra inteiramente dedicada à história dos projetos de Brasil gestados entre a segunda metade do século XVIII e as primeiras décadas do XIX é uma novidade.

Se o Brasil nasce no século XIX, não resta dúvida de que a sua concepção principiou ainda no século anterior, na encruzilhada dos projetos e formulações desses letrados, com todos os dilemas e paradoxos típicos de uma época de transição. Seus escritos - fundamentais para se entender o processo de concepção, gestação e parto do Brasil como nação autônoma - fornecem a matéria-prima sobre a qual Malerba se debruça ao longo dos 17 capítulos que compõem o livro, perscrutando neles, entre outras coisas, a natureza do diálogo que encetaram com a Ilustração. Afinal, o problema da assimilação do ideário iluminista em Portugal ainda permanece um debate em aberto - e aqui reside, sem dúvida, uma das teses centrais do livro, sobre a qual se assenta toda a sua estrutura analítica. Ao contrário das correntes historiográficas que tendem a exagerar a sua influência na agenda do reformismo ilustrado, ou mesmo a negá-la por completo, o autor sublinha os limites estreitos do chamado iluminismo português, expressos pela apropriação seletiva de alguns dos seus aspectos, como o pragmatismo e o utilitarismo. Essa versão portuguesa, esvaziada de noções como autonomia e liberdade individual, não esteve a serviço da emancipação do homem pela razão, mas tão somente de um projeto de maximização da exploração do mundo colonial, e, como tal, da manutenção da velha ordem.

Dos textos desses letrados, emergem diferentes visões do futuro do Brasil. De pena em punho, mobilizaram as ferramentas que estavam ao seu alcance para traçar as linhas mestras de um Brasil sonhado por poucos, relegando ao silêncio as vozes da imensa maioria. Com os pés fincados no presente, o autor esmiúça, escrutina, vira e revira do avesso os projetos formulados pelas elites, procurando identificar as raízes distantes das mazelas da sociedade brasileira, como a exclusão, a desigualdade e a pobreza. É irresistível pensar na distância que separa o entusiasmo ingênuo dos primeiros cronistas do século XVI, convencidos de que no Brasil estava localizado o paraíso terrestre, para o qual anunciavam um futuro de prosperidade e riqueza, e o cálculo frio e técnico desses letrados dos fins do século XVIII e início do XIX, que, munidos de régua e compasso, não hesitaram em projetar o inferno de muitos.

Ao longo do livro, Malerba vai desmontando algumas armadilhas em que ficaram presas mais de uma geração de estudiosos, e, num tom vigoroso e crítico, expõe a construção ideológica que se esconde por trás de conceitos tão difundidos como "império luso-brasileiro", "abrasileiramento da burocracia" e "pacto colonial", posicionando-se vigorosamente contra determinados lugares-comuns da historiografia, cristalizados por certa tradição pouco questionada, que, à maneira do método de Koselleck (1993), é preciso relativizar senão abolir. Que os discursos não espelham a realidade, mas buscam sobretudo atuar sobre ela é uma lição que, nos últimos tempos, tem sido esquecida pelos estudiosos, que, enfeitiçados pelas 
palavras, parecem convencidos de que a forma como uma sociedade descreve e representa a si mesma expressa a sua verdade mais profunda.

Organizado cronologicamente, o livro examina, na primeira parte, as reformas propostas entre a época pombalina e Azeredo Coutinho, compreendendo a geração de 1790, da qual o bispo era um dos expoentes. Letrados, saídos das fileiras da nobreza civil, ainda que compartilhassem de diagnósticos parecidos sobre os males de que padecia Portugal e seus domínios ultramarinos, diferenças significativas os separavam. Tendo por pano de fundo a manutenção da unidade do império por meio da adoção de um conjunto de reformas administrativas, econômicas e fiscais nas colônias, esses projetos, marcados pelo utilitarismo das Luzes, permaneceram presos ao mundo do Antigo Regime, cuja estrutura visavam preservar da influência das novas ideias e dos novos tempos. Questões sobre o desenvolvimento econômico, a escravidão, as populações indígenas, o lugar do Brasil na reconfiguração das relações da metrópole com as suas colônias são cuidadosamente examinadas pelo autor, interessado também em apontar as determinações políticas e de classe social sobre o alcance e escopo desses projetos. Se as diferentes formas de apropriação das Luzes constituem um dos fios que conduz a análise, não é menos verdade que Malerba jamais perde de vista as implicações sociais dessas formulações, de modo a responder a uma indagação que, do começo ao fim, atravessa todas as páginas: que sociedade esses projetos buscavam instaurar no Brasil?

A segunda parte é dedicada às circunstâncias históricas que motivaram a vinda da corte para os trópicos e às propostas de José da Silva Lisboa, o visconde de Cairu, passando pelos impactos políticos, sociais e econômicos decorrentes da mudança do centro da monarquia para o Rio de Janeiro, sobretudo a emergência de uma elite brasileira gestada a partir da lógica da corte. No capítulo sobre o visconde de Cairu, tido como o inaugurador do pensamento liberal no Brasil, o autor explora o caráter conservador de suas concepções, manifesto sobretudo nos temas relativos ao tráfico negreiro e à escravidão. Ainda sob a influência dos reformadores do século anterior, estava fora do seu programa a autonomia política do Brasil, reduzido, como no passado, à condição colonial, e cuja ruptura via, como leitor entusiasmado de Burke, com maus olhos.

A terceira parte analisa o contexto histórico da independência, as disputas em torno das cortes gerais e extraordinárias, as tensões que tiveram lugar nos dois lados do Atlântico, a ruptura política e a atuação de José Bonifácio de Andrada e Silva. Para melhor situar o leitor, um breve preâmbulo fornece um quadro geral dos anos que precederam à independência, com foco sobretudo nas implicações da vinda da corte. Todo o burburinho frenético dos anos que vão de 1820 a 1824 é captado com o recurso às fontes e a uma bibliografia bastante atualizada; e nessa narrativa trepidante dos eventos também têm lugar as lutas entre os diferentes grupos sociais em torno do significado da emancipação política, e a obra de exclusão e silenciamento da população livre e pobre ao longo desse processo. 
O pano de fundo do livro repousa sobre os dilemas de uma época a cavaleiro de dois mundos: de um lado, os valores do Antigo Regime, a defesa da monarquia e dos privilégios da nobreza, a tradição; de outro, os novos ventos soprados pela Ilustração e pela Revolução Francesa, o culto da razão e da ciência, a emergência do liberalismo. Nascidos sob o Antigo Regime, no qual forjaram as suas visões de mundo, esses reformadores se viram às voltas com um mundo novo, com o desafio hercúleo de conciliar extremos tão opostos. É nesse delicado fio de navalha que eles se movem, esgueirando-se entre as ruínas da velha ordem e os fundamentos da incipiente ordem burguesa e liberal. Daí a natureza ambígua e contraditória dos seus escritos, a forma como oscilam entre a apropriação das Luzes e, ao mesmo tempo, a lealdade às velhas doutrinas.

Há muitas maneiras de se ler Brasil em projetos. Apesar da ordem cronológica dos capítulos, esses podem ser lidos em qualquer ordem e separadamente. De leitura agradável, a escrita de Malerba, expurgada dos jargões acadêmicos, corre solta e límpida, sem jamais perder de vista a profundidade dos assuntos de que trata, comprovando a tese de que é possível escrever para um público amplo, sem prejuízo da qualidade.

Dentre todas as possibilidades de leitura desse livro, talvez a mais importante, constantemente sinalizada pelo autor, é apreendê-lo como uma reflexão sobre a tradição conservadora brasileira, que, inaugurada no início da colonização, ainda no século XVI, encontra-se vigorosa nos discursos dos reformadores e planejadores ao longo de todo o período estudado, como se pode ver em suas propostas, nas quais a escravidão, a desigualdade social, a exploração das populações indígenas são pontos programáticos, respondendo a interesses políticos e econômicos dos grupos dominantes. O Brasil que horrorizaria os viajantes europeus ao longo de todo o século XIX, escandalizados com a escravidão e a miséria, é, em grande parte, obra desses homens.

Talvez venha daí o travo amargo que Brasilem projetos provoca no leitor. Ainda que outros propostas alinhadas com uma pauta mais progressista e de caráter republicano tenham sido formuladas, a exemplo das Inconfidências carioca e baiana e a Revolução de 1817, o certo é que a pena dos letrados não só gozou de uma legitimidade indiscutível, em razão de sua inserção nos quadros do governo, mas também demarcou o campo de possibilidades para o futuro da colônia e, mais tarde, da nação, de acordo com as perspectivas de uma elite interessada na manutenção dos seus privilégios de classe.

É por essa razão que o livro de Malerba também nos dá uma chave valiosa para entendermos o Brasil dos nossos dias. Mais do que nunca, a história deve ser, para nós, esse exercício de reflexão sobre o presente, o gesto doloroso, porém, necessário de expor as entranhas de um passado que ainda nos habita e assombra, para esconjurar os silêncios, as mitologias e negacionismos desses tempos sombrios. 


\section{Referências}

ALEXANDRE, Valentim. Os sentidos do Império: questão nacional e questão colonial na crise do Antigo Regime português. Porto: Afrontamento, 1993.

BOXER, Charles. O império marítimo português (14151825). Lisboa: Edições 70, 2001.

FALCON, Francisco José Calazans. A época pombalina: política econômica e monarquia ilustrada. São Paulo Ática, 1982.

JANCSÓ, István. (Org.). Independência: história e historiografia. São Paulo: Hucitec, Fapesp, 2005.

KOSELLECK, Reinhart. Futuro pasado. Para una se- mántica de los tiempos históricos. Barcelona: Paidós, 1993.

MAXWELL, Kenneth. Conflicts and conspiracies: Brasil o Portugal 1750-1808. Cambridge: Cambridge University Press, 1973.

NOVAIS, Fernando. Portugal e Brasil na crise do antigo sistema colonial (1777-1808). São Paulo: Hucitec, 1986.

PIMENTA, João Paulo G. A independência do Brasil. Um balanço da produção historiográfica recente. In: CHUST, M.; SERRANO, J. A. (Eds.). Debates sobre las independencias ibero-americanas. Madrid/Frankfurt: Iberoamericana, 2007, p. 147-158. 